Geografia e Ordenamento do Território, Revista Electrónica

Centro de Estudos de Geografia e Ordenamento do Território

http://cegot.org

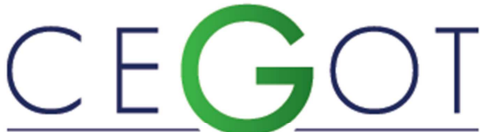

ISSN : 2182-1267

Centro de Estudos de Geografia

Pinheiro, $\mathrm{C}$.

e Ordenamento do Território

Universidade do Minho

catarina-pinheiro@mail.com

Laranjeira, M.

Departamento de Geografia da Universidade do Minho; CEG

manuela.laranjeira@geografia.uminho.pt

\title{
Análise do ambiente térmico e das condições de ventilação para a definição das funções climáticas na área urbana de Guimarães
}

Referência: Pinheiro, C.; Laranjeira, M. (2013). Análise do ambiente térmico e das condições de ventilação para a definição das funções climáticas na área urbana de Guimarães. Revista de Geografia e Ordenamento do Território (GOT), n. 4 (dezembro). Centro de Estudos de Geografia e Ordenamento do Território, p. 249-272

\section{Resumo}

Diversas funções climáticas foram definidas e avaliadas para a área urbana de Guimarães, tendo por base a análise conjunta do padrão espacial da temperatura de superfície $\left(T_{s}\right)$ e da ventilação. Para tal, examinou-se a relação entre $T_{s}$ e os usos do solo, distinguidos através dos índices NDVI, NDBI, NDWI e NDBal, que, por sua vez, foram derivados a partir de uma imagem do satélite Landsat 7 ETM+. Por outro lado, o padrão da ventilação foi determinado em função da topografia (classes de ventilação). Na sequência desta análise, a produção de ar frio, a renovação do ar e os corredores de ventilação assumiram-se como as principais funções desempenhadas pelos diferentes climatopos da área de estudo.

Palavras-Chave: temperatura de superfície, NDVI, NDBI, NDWI, NDBal, classes de ventilação, climatopos, funções climáticas 


\begin{abstract}
Climatic functions were defined and assessed for Guimarães urban area by combining land surface temperature $\left(T_{s}\right)$ and ventilation spatial patterns. Therefore, the relationship between $T_{s}$ and land use types was examined. These were derived from NDVI, NDBI, NDWI and NDBal indices, using data collected by the Landsat 7 ETM+ remote sensing system. On the other hand, ventilation conditions were determined, as a function of topography (ventilation classes). As a result of this analysis, cool air production, air renovation and ventilation paths were found to be the primordial climatic functions performed by the study area's climatopes.
\end{abstract}

Keywords: land surface temperature, NDVI, NDBI, NDWI, NDBal, ventilation classes, climatopes, climatic functions

\title{
1. Introdução
}

A recente utilização de dados de deteção remota, captados na região do infravermelho térmico, veio permitir a análise das temperaturas de superfície $\left(T_{s}\right)$. Para Weng (2009), $T_{s}$ constitui um importante parâmetro nos estudos do clima urbano, uma vez que modela a temperatura do ar da atmosfera urbana inferior, correspondendo a um dos fatores principais na determinação dos fluxos de energia. Com efeito, $T_{s}$ tem sido analisada no contexto do balanço radiativo e energético urbano (Lopes, 2003, 2008), na sua relação com as propriedades físicas das superfícies (Deng e $\mathrm{Wu}, 2013$ ), a repartição espacial dos usos do solo (Wilson et al., 2003; Weng et al., 2004; Chen et al., 2006; Eum et al., 2011; Xiong, 2012), a configuração espacial dos usos do solo (Cao et al., 2010; Zhou et al., 2011), bem como na relação com diferentes tipologias urbanas e índices urbanísticos (Zhao et al., 2011; Costa e Laranjeira, 2012). Qualquer dos trabalhos citados revela que os núcleos urbanos compreendem um mosaico de áreas quentes e frescas, em função dos diferentes usos do solo. Estas diferenças de $T_{s}$ e da temperatura do ar podem induzir a advecção do ar fresco em direção aos locais onde o calor se acumula (Spronken-Smith e Oke, 1998; Cao et al., 2010). Por sua vez, o vento (regional e local) desempenha um papel fundamental no ambiente climático urbano, pois contribui para o arejamento e renovação do ar, atuando positivamente no conforto térmico e na qualidade do ar (Alcoforado et al., 2005). Neste sentido, a topografia e a sua influência sobre a ventilação devem ser integradas nos estudos do clima urbano (Scherer et al., 1999), particularmente no caso de vales densamente urbanizados, onde a existência e 
salvaguarda de áreas a montante que produzam ar frio, assim como a ausência de obstáculos à sua drenagem para jusante (Andrade, 2003), são fatores determinantes a minimização dos impactes da urbanização sobre os aumentos indesejáveis da temperatura.

Atendendo a que os problemas climáticos mais frequentes nas áreas urbanas se encontram associados à componente térmica e à circulação do ar (Alcoforado et al., 2005), torna-se fundamental analisar as características do uso do solo, sob a perspetiva da carga térmica, e as condições de ventilação que asseguram a renovação do ar (Acero et al., 2013). A partir da análise conjunta destes fatores climáticos é possível identificar e caracterizar diferentes climatopos (Acero et al., 2013) - i.e., áreas com características relativamente homogéneas, que potencialmente apresentarão uma resposta climática semelhante (Scherer et al., 1999; Alcoforado et al., 2005, 2009). Neste trabalho, analisou-se, para a área urbana de Guimarães, o padrão espacial de $T_{s}$, procurando-se estabelecer a sua relação com os usos do solo (derivados a partir de índices espectrais), de modo a avaliar a carga térmica. Por sua vez, o padrão da ventilação foi analisado em função da topografia (classes de ventilação). Na sequência desta análise, foram determinadas e avaliadas as principais funções climáticas que os diversos climatopos desempenham, fundamentais na regulação do clima urbano.

\section{Metodologia}

\section{1. Área de Estudo}

Este trabalho debruçou-se sobre a área urbana de Guimarães e a sua envolvente topográfica - doravante designada apenas por área urbana de Guimarães -, definida em função do perímetro urbano, de acordo com os dados referentes ao ano de 2010 fornecidos pela Câmara Municipal de Guimarães (CMG), e recorrendo aos interflúvios circundantes como elemento de fronteira (Figura 1). Dada a escala climática do estudo clima local e mesoclima (Andrade, 2005) -, a área de análise estabelecida permite ter em consideração os processos dinâmicos que se fazem sentir no perímetro urbano, mas têm uma distribuição espacial mais alargada e/ou são interdependentes de outros processos com sede exterior a esta delimitação administrativa. 

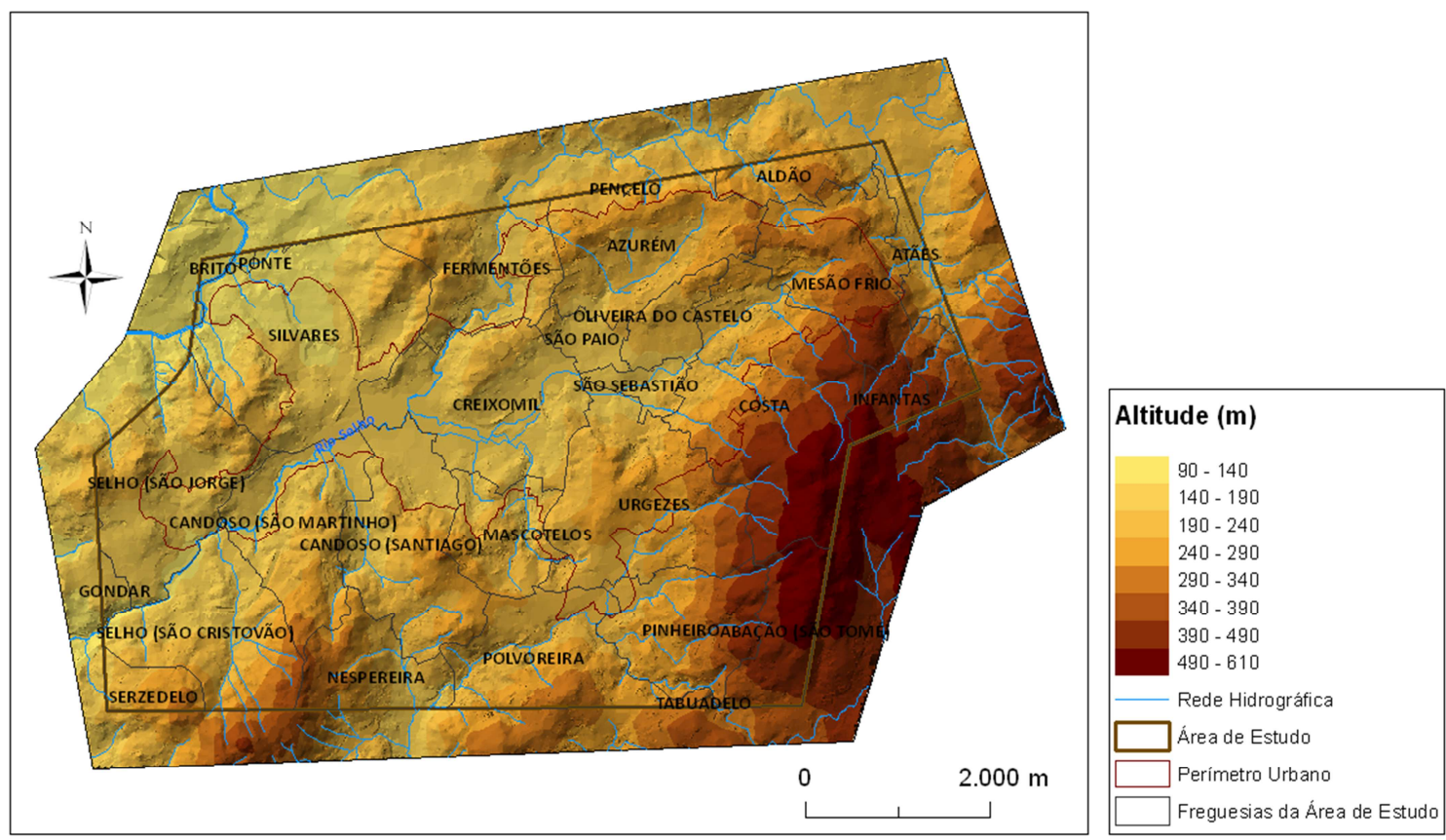

Figura 1 - Enquadramentos topográfico e administrativo da área urbana de Guimarães

(Fonte dos dados: Carta Administrativa Oficial de Portugal (CAOP), 2012e CMG)

\subsection{Derivação das temperaturas de superfície}

A partir do processamento da banda 6.1 (região do infravermelho térmico) da imagem do satélite Landsat 7 ETM+ de 24/06/2000, às 10h (hora local), com uma cobertura de nuvens de $60 \%$, derivou-se $T_{s}$ para a área urbana de Guimarães. Note-se que a área estudada não foi diretamente afetada por esta cobertura de nuvens. A imagem utilizada diz respeito ao período do dia em que as diversas superfícies se encontram ainda a aquecer, pelo que a informação obtida não traduz os valores máximos de $T_{s}$ que se podem atingir (Bonan, 2000). Na realidade, o facto da captação de imagens pelo satélite Landsat 7 ETM+ se realizar sempre à mesma hora representa uma limitação, pois não permite analisar os fenómenos típicos da tarde e da noite. Para obter $T_{s}$ foi necessário recalcular os valores de radiância espectral no sensor $\left(L_{\lambda}\right)$ a partir do número digital (DN) associado a cada pixel da imagem (resolução espacial de $60 \mathrm{~m}$ ), segundo o procedimento descrito pelo Landsat Project Science Office (2001). Assim, $L_{\lambda}$ é dada pela equação:

$$
L_{\lambda}=\left(\left(L_{M A X}-L_{\lambda} M N_{\lambda}\right) /(Q C A L M A X-Q C A L M I N)\right) *(Q C A L-Q C A L M I N)+L_{M I N}
$$

em que,

$\mathrm{L}_{\lambda}=$ radiância espectral no sensor $\left(\mathrm{Wm}^{-2} \mathrm{sr}^{-1} \mu \mathrm{m}^{-1}\right)$ 
$\mathrm{QCAL}=$ valor do pixel $(\mathrm{DN})$

$\mathrm{LMIN}_{\lambda}=$ radiância espectral mínima (dimensionada para QCALMIN) $=0,00 \mathrm{Wm}^{-2} \mathrm{sr}^{-1} \mu \mathrm{m}^{-1}$

$\mathrm{LMAX}_{\lambda}=$ radiância espectral máxima (dimensionada para QCALMAX) $=17,04 \mathrm{Wm}^{-2} \mathrm{sr}^{-1} \mu \mathrm{m}^{-1}$

QCALMIN = valor mínimo do pixel $(D N)=1$

QCALMAX $=$ valor máximo do pixel $(D N)=255$

Posteriormente, e sob o pressuposto de uma emissividade uniforme, converteram-se os valores de radiância espectral em $\mathrm{T}_{\mathrm{s}}$, através da seguinte fórmula:

$$
T_{s}=\frac{K 2}{\ln \left(\frac{K 1}{L_{\lambda}}+1\right)}
$$

em que,

$\mathrm{T}_{\mathrm{s}}=$ temperatura de superfície $(\mathrm{K})$

$\mathrm{K} 2$ = constante de calibração $2=1282,71 \mathrm{~K}$

$\mathrm{K} 1$ = constante de calibração $1=666,09 \mathrm{Wm}^{-2} \mathrm{sr}^{-1} \mu \mathrm{m}^{-1}$

$\mathrm{L}_{\lambda}=$ radiância espectral no sensor $\mathrm{Wm}^{-2} \mathrm{sr}^{-1} \mu \mathrm{m}^{-1}$

Por fim, os valores de $T_{s}$ foram convertidos de Kelvin para graus Celsius.

Diferentes $T_{\mathrm{s}}$ resultam de distintas propriedades radiativas e térmicas dos materiais em particular, o albedo, a emissividade e a condutividade térmica -, que determinam o modo como a radiação solar é por eles refletida e o calor é armazenado, emitido e libertado na atmosfera urbana inferior influenciando, por consequência, os valores da temperatura do ar (Lopes, 2008). Nas áreas urbanas, as $T_{s}$ são, em geral, mais elevadas do que nos arredores porque os materiais artificiais que as constituem são mais eficientes no armazenamento da energia solar, podendo reter duas vezes mais calor do que as áreas rurais vizinhas (Costa et al., 2010).

\subsection{Derivação dos índices NDVI, NDWI, NDBI e NDBal}

Tirando partido da resposta singular das diferentes superfícies a uma determinada região do espectro eletromagnético, combinações apropriadas entre as bandas das imagens multiespectrais de satélite têm servido de base ao desenvolvimento de um conjunto de índices, que procuram discriminar de forma automática os principais tipos 
de cobertura ou uso do solo. Utilizando a banda 3 (vermelho), banda 4 (infravermelho próximo), banda 5 (infravermelho médio) e, novamente, a banda 6.1 da imagem do satélite Landsat 7 ETM+ de 24/06/2000, derivaram-se quatro índices para a área urbana de Guimarães: um índice de vegetação, NDVI (Normalized Difference Vegetation Index), proposto em 1973 e dos mais amplamente usados (Armas e Caetano, 2005); um índice sensível à água, NDWI (Normalized Difference Water Index; Gao, 1996); um índice para o reconhecimento da construção (espaços edificados), NDBI (Normalized Difference BuiltUp Index; Zha et al., 2003); e, um índice que distingue o solo nu, NDBal (Normalized Difference Bareness Index; Zhao e Chen, 2005). Com base na classificação destes índices, distinguiram-se os usos do solo na área de estudo, recorrendo, para tal, a intervalos de classe apropriados, indicados por Chen et al. (2006).

O índice NDVI pode ser utilizado para estimar a cobertura vegetal, sendo sensível a um largo intervalo de densidade da vegetação (Purevjdoj et al., 1998). O NDVI é obtido através da seguinte equação:

$$
N D V I=(d(\text { banda } 4)-d(\text { banda } 3)) /(d(\text { banda } 4)+d(\text { banda } 3))
$$

em que,

$d=$ valor do pixel (DN) das bandas 4 e 3 da imagem Landsat 7 ETM+

Segundo Chen et al. (2006), é importante analisar conjuntamente os índices NDVI e NDWI de forma a avaliar o estado da vegetação, uma vez que NDWI permite determinar o conteúdo de água na vegetação com base em princípios físicos (Gao, 1996). Este índice é dado pela fórmula:

$$
N D W I=(d(\text { banda } 4)-d(\text { banda })) /(d(\text { banda } 4)+d(\text { banda }))
$$

em que,

$d=$ valor do pixel (DN) das bandas 4 e 5 da imagem Landsat 7 ETM+

Relativamente ao índice NDBI, este é derivado a partir da equação:

$$
N D B I=(d(\text { banda } 5)-d(\text { banda } 4)) /(d(\text { banda } 5)+d(\text { banda } 4))
$$

em que,

$d=$ valor do pixel (DN) das bandas 5 e 4 da imagem Landsat 7 ETM+ 
O índice NDBI é incapaz, segundo os seus autores, de separar espaços industriais, comerciais e residenciais; contudo, esta limitação poderá não ser relevante nas áreas urbanas onde estes espaços se encontram espacialmente mesclados (Zha et al., 2003), como no caso de Guimarães. Por outro lado, o desempenho do NDBI pode ser negativamente afetado pela presença de outros usos do solo cuja refletância varia sazonalmente (Zha et al., 2003). Isto sucede em relação aos solos agrícolas, pois uma vez a descoberto, apresentam uma resposta espectral similar à das áreas construídas. Tendo em conta que a imagem de satélite utilizada no presente trabalho foi captada no final de junho, e que, nessa altura, os solos agrícolas incluídos no perímetro urbano de Guimarães se encontram lavrados (i.e., sem qualquer tipo de coberto vegetal), recorreuse ao índice NDBal de forma a apurar a análise dos resultados de NDBI. A equação de NDBal é a que se segue:

$$
N D B a I=(d(\text { banda } 5)-d(\text { banda6 })) /(d(\text { banda } 5)+d(\text { banda }))
$$

em que,

$d=$ valor do pixel (DN) das bandas 5 e 6 da imagem Landsat 7 ETM+

Todas as operações necessárias à derivação dos índices foram realizadas através da ferramenta Raster Calculator (Map Algebra), da extensão Spatial Analyst do ArcGIS 10.1/ ArcMap. Note-se que, por se tratar de índices normalizados, NDVI, NDWI, NDBI e NDBal variam entre -1 e 1.

\subsection{Determinação das temperaturas de superfície por usos do solo}

Para o maior entendimento da relação entre $T_{s}$ e os usos do solo, a assinatura térmica de cada um deve ser examinada (Weng et al., 2004). Neste sentido, definiram-se dois perfis de amostragem que, passando pelo núcleo urbano de Guimarães, atravessam diversos usos do solo, desde parcelas agrícolas com solo nu a áreas densamente florestadas (Figura 2). O traçado dos perfis, com pontos equidistantes de $100 \mathrm{~m}$, foi realizado com recurso ao ArcGIS 10.1/ ArcMap. O perfil 1, designado por centro da cidade - encosta da Penha, tem uma extensão de $2,3 \mathrm{~km}$, enquanto o perfil 2, veiga de Creixomil - Parque da Cidade, se estende por 6,2 km. Assim, optou-se por amostrar, neste último perfil, apenas os pontos que distam entre si $200 \mathrm{~m}$. No conjunto dos dois 
perfis, estabeleceu-se uma amostra de 56 pontos. Os valores de $T_{s}, N D V I, N D W I, N D B I$ e NDBal relativos a cada um destes pontos foram extraídos através da ferramenta Extract by Points (Extraction), da extensão Spatial Analyst do ArcGIS 10.1/ ArcMap. As cinco séries de dados resultantes foram submetidas ao teste de normalidade de Shapiro-Wilk, verificando-se que nenhuma delas segue uma distribuição normal. Como tal, na análise estatística destes dados recorreu-se a um teste de hipótese não-paramétrico, designadamente o teste de correlação ordinal de Spearman, que avalia até que ponto a ordem dos valores (e não os valores per se) nas séries de duas variáveis exibe uma associação perfeitamente monótona (Townend, 2002).

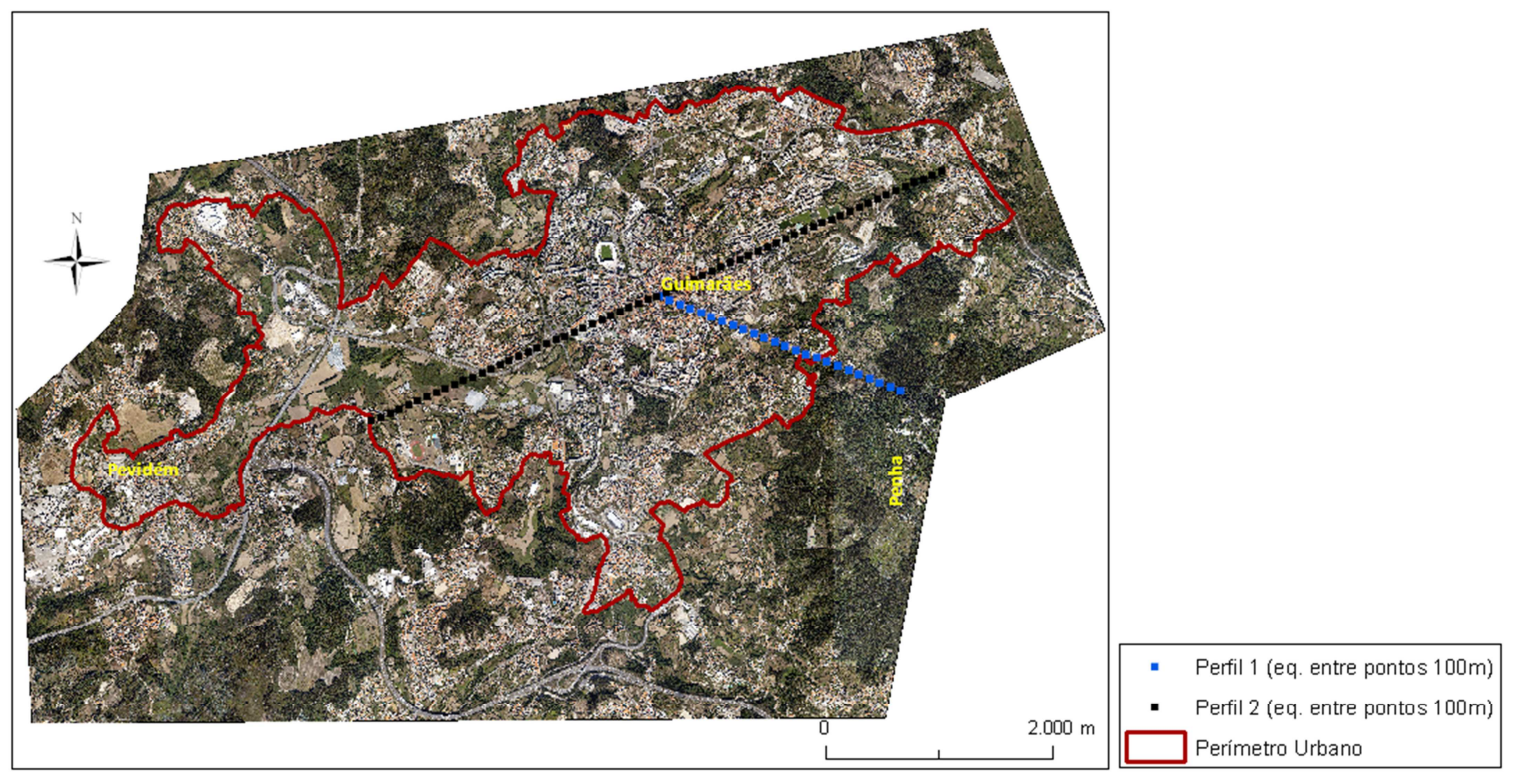

Figura 2 - Ocupação do solo na área urbana de Guimarães e localização dos perfis de amostragem

(Fonte dos dados: $\mathrm{CMG}$ )

Os limiares de NDVI, NDWI, NDBI e NDBal utilizados para classificar os diferentes usos do solo, a partir da amostra dos 56 pontos, tiveram como referência os sugeridos por Chen et al. (2006). Assim, distinguiram-se quatro classes: vegetação $(\mathrm{NDBl}<0)$; construção ( $N D B \mid \geq 0,1$ e $N D V I<0$ e NDBal $\leq 0$ ); solo nu/pavimento (NDBI $\geq 0,1$ e $N D B a l>0$ ); e, misto $(0 \leq N D B \mid<0,1$, ou $N D B \mid \geq 0,1$ e $N D V I \geq 0$ e NDBal $\leq 0)$.

\subsection{Definição das classes de ventilação e dos climatopos}

A metodologia para a definição das classes de ventilação e dos climatopos, na área urbana de Guimarães, teve como referência o trabalho de Alcoforado et al. $(2005,2009)$ 
para Lisboa. As classes de ventilação traduzem a interação entre os fatores climáticos que controlam a circulação do ar, ao nível local e regional, e os processos verticais de substituição das massas de ar, que resulta em condições de ventilação características e distintas (Scherer et al., 1999). De acordo com os autores citados, as classes de ventilação são delimitadas em função de diferentes posições topográficas (fundo do vale, vertente, topo); no entanto, no presente estudo considerou-se igualmente a presença de socalcos nas vertentes. Assim, foram definidas três unidades de relevo: topos com altitude superior a $340 \mathrm{~m}$; topos com altitude inferior a $340 \mathrm{~m}$ e vertentes (diferenciadas em função do declive e da existência de socalcos); e, fundo do vale. 0 limite dos $340 \mathrm{~m}$ permitiu salientar os relevos mais proeminentes, numa área em que a variação altitudinal não é, em geral, muito acentuada (Figura 1). A morfologia urbana constitui outro dos principais fatores do clima urbano, sendo que Alcoforado et al. $(2005,2009)$ a consideraram em função da densidade da área edificada. Utilizando o mesmo critério, neste trabalho foram definidas três classes de densidade de ocupação urbana, designadamente 'baixa', 'média a baixa' e 'elevada'. Este parâmetro foi obtido através de duas fontes de informação: (i) a delimitação das áreas com solo urbano, efetuada pela Direção Regional de Agricultura e Pescas do Norte (DRAPN); e, (ii) a informação do edificado da CMG (Pinheiro, 2012).

Como resultado do cruzamento entre as classes de ventilação e a densidade urbana, cinco climatopos foram definidos na área urbana de Guimarães: A - topos (altitude $>340 \mathrm{~m}$ ), com baixa densidade urbana; B - topos (altitude $<340 \mathrm{~m}$ ) e vertentes, com densidade urbana média a baixa; $C$ - topos (altitude $<340 \mathrm{~m}$ ) e vertentes, com elevada densidade urbana; D - fundo do vale, com baixa densidade urbana; E - fundo do vale, com elevada densidade urbana.

\section{Resultados e Discussão}

\subsection{Padrão espacial da temperatura de superfície}

$\mathrm{Na}$ área urbana de Guimarães verifica-se uma acentuada variação dos valores de $T_{s}$

(Figura 3) entre as áreas exteriores ao perímetro urbano de Guimarães, mais arborizadas, e as que Ihe são interiores, com maior densidade de construção (Figura 2), 
podendo-se atingir mais de $10^{\circ} \mathrm{C}$ de diferença. Por sua vez, as áreas agrícolas, incluídas no perímetro urbano, podem registar $\mathrm{T}_{\mathrm{s}}$ tão elevadas quanto as das superfícies nas áreas mais densamente urbanizadas (Figura 2 e 3). Através da Figura 3, é possível reconhecer, em grandes traços, os locais de acumulação e produção de calor (por radiação de longo comprimento de onda e calor sensível) - i.e., as ilhas de calor urbano superficial (a única ilha de calor que a variação de $T_{s}$ permite identificar diretamente, de acordo com Lopes (2008)) -, bem como os locais de menor produção de calor (devido à libertação de calor latente) - i.e., as ilhas de frescura superficial (Cao et al., 2010). Nesta sequência, as principais ilhas de calor formam-se no núcleo urbano central de Guimarães, Pevidém e Urgezes, e, por oposição, no parque urbano do monte da Penha tem lugar a principal ilha de frescura (Figura 3), dada a sua densa florestação.

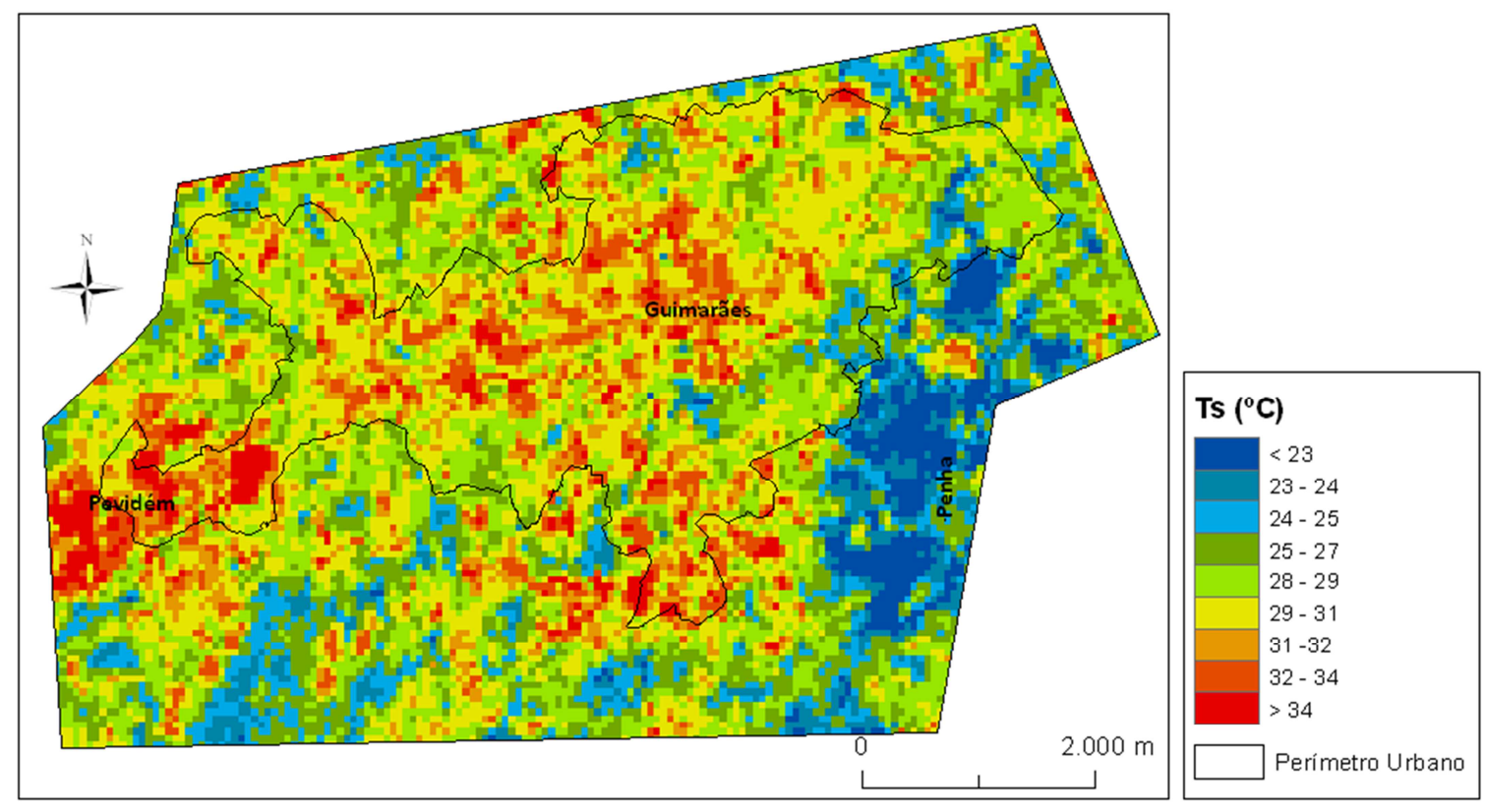

Figura 3 - Temperatura de superfície $\left(T_{s}\right)$, às $10 \mathrm{~h}$ de 24/06/2000, na área urbana de Guimarães (Fonte dos dados: Landsat 7 ETM+ e CMG)

A relação entre $T_{s}$, NDVI e NDBI tem sido documentada em diversos estudos (Chen et al., 2006; Xiong et al., 2012). Comparando os mapas das Figuras 3 e 4, verifica-se que às áreas com $T_{s}$ mais elevadas correspondem os valores de $N D V I<0,2$, de $N D B a l>0$ e de $\mathrm{NDB} \mid>0,25$, dada a ausência de cobertura vegetal arbórea e à predominância de urbanização densa. Na realidade, a substituição da vegetação por materiais de construção - em que a transpiração não se processa - e a presença de solo agrícola sem coberto vegetal - onde aquele fenómeno é muito reduzido - resultam no aumento 
significativo de $T_{s}$, como é patente na relação espacial entre esta variável e NDWI. A análise da correlação entre $T_{\mathrm{s}}$ e os índices estudados, efetuada com base na amostra dos perfis 1 e 2 (Figura 2), reforça estes resultados (Tabela 1). É notória a correlação positiva entre NDVI e NDWI que, por sua vez, apresentam correlações negativas com NDBI e NDBal. Como seria de esperar, NDVI e NDWI correlacionam-se negativamente com $T_{s}$, ao contrário de NDBI e NDBal.

Tabela 1 - Coeficientes $\rho$ do teste de correlação de Spearman $(p<0,0001)$ entre $T_{s}, N D W I, N D V I, N D B I$ e NDBal

\begin{tabular}{c|ccccc}
\hline Variáveis & NDWI & NDVI & NDBI & NDBal & $\mathbf{T}_{\mathbf{s}}$ \\
\hline NDWI & 1 & & & & \\
NDVI & 0,917 & 1 & & & \\
NDBI & $-1,000$ & $-0,917$ & 1 & & \\
NDBal & $-0,598$ & $-0,537$ & 0,598 & 1 & \\
$\mathbf{T}_{\mathbf{s}}$ & $-0,739$ & $-0,702$ & 0,739 & 0,633 & 1 \\
\hline
\end{tabular}

Os dois perfis de amostragem (Figuras 5 e 6) põem em evidência o gradiente térmico das superfícies entre o núcleo central de Guimarães e os arredores, sobretudo no caso do perfil centro da Cidade - encosta da Penha (perfil 1). Neste perfil (Figura 5), as elevadas $\mathrm{T}_{\mathrm{s}}$ que caracterizam a área urbana densa correlacionam-se com os valores mais altos de NDBI e, simultaneamente, com NDVI, NDWI e NDBal negativos. Na transição desta área para os campos agrícolas, com povoamento disperso (600-900m), uma miscelânea de usos do solo traduz-se numa variação mais complexa dos índices analisados e de $T_{s}$. $A$ partir da área agrícola, e ao longo da encosta da Penha, os valores de NDVI e NDWI elevam-se (assumindo valores positivos), enquanto NDBI e NDBal se mantêm negativos; assim, verifica-se a gradual diminuição dos valores de $T_{s}$ registados. 

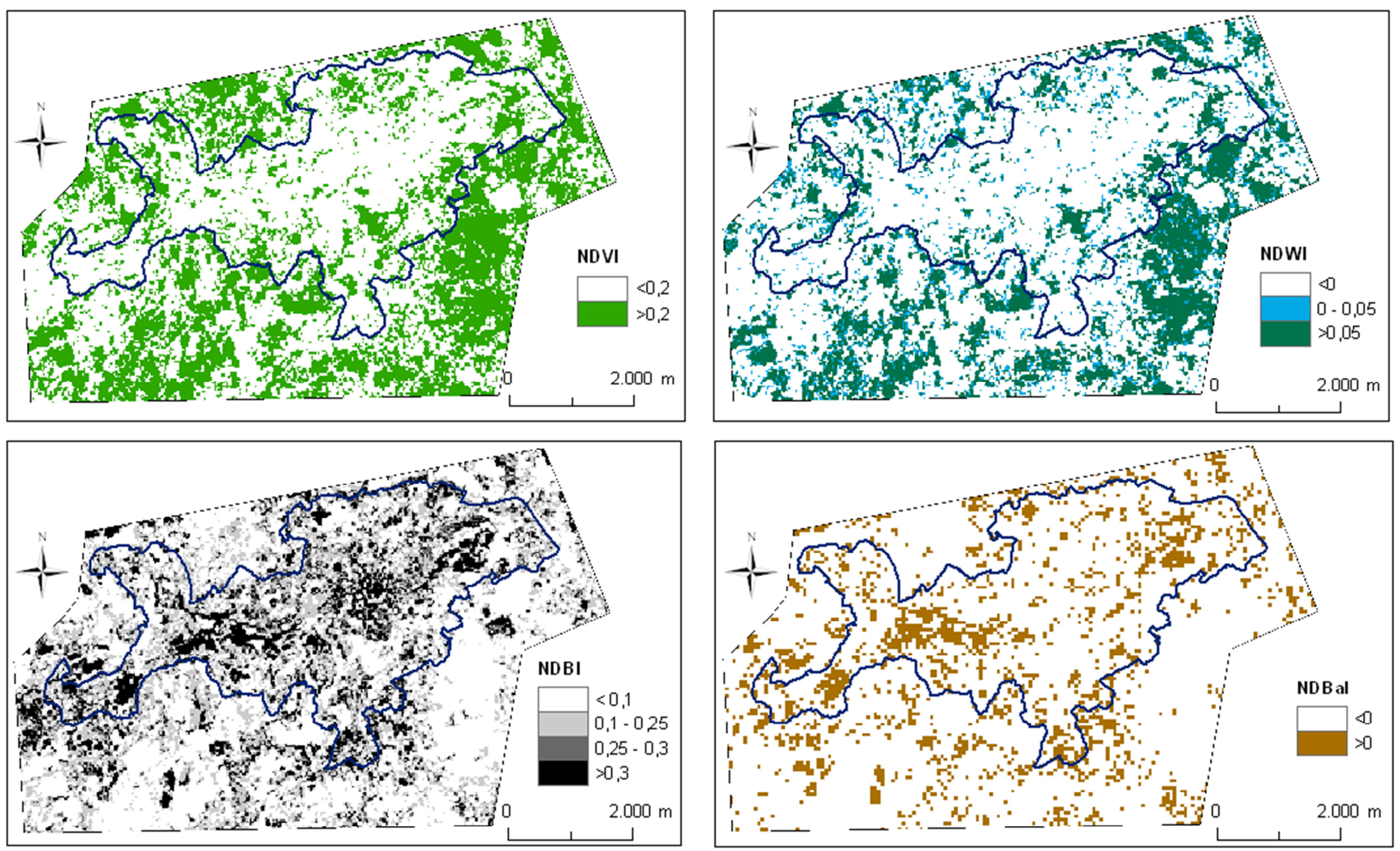

Figura 4 - Classes significativas de NDVI, NDWI, NDBI e NDBal, às 10h de 24/06/2000, na área urbana de Guimarães (a linha a azul representa o perímetro urbano de Guimarães; Fonte dos dados: Landsat 7 ETM+ e CMG) 
O perfil veiga de Creixomil - Parque da Cidade (perfil 2) é mais complexo que o anterior (Figura 6), uma vez que atravessa um mosaico muito mesclado de usos do solo. Na veiga de Creixomil, que se encontra dividida por uma via rodoviária, a intercalação entre parcelas agrícolas com solo lavrado e faixas de vegetação arbórea origina uma heterogeneidade espacial de superfícies com respostas espectrais e comportamentos térmicos muito diversos. Por sua vez, na área do Parque da Cidade ocorre uma diminuição acentuada (embora não linear) de $T_{s}$, apesar de NDVI e NDBI manterem valores semelhantes aos do centro cidade. Tal dever-se-á ao facto de os pontos amostrados coincidirem com locais menos arborizados e áreas pavimentadas (Figura 2). A influência climática das áreas verdes é muito limitada no espaço (Andrade e Vieira, 2007), sendo que, segundo Leal et al. (2008), esta não depende diretamente das suas dimensões mas da respetiva composição vegetal. Com efeito, observa-se, ao longo dos perfis, que nas áreas onde a vegetação arbórea não é tão densa ou não existe (como na veiga de Creixomil), as $T_{s}$ aumentam consideravelmente,comprovando a importância da arborização para a sua redução efetiva, mais do que qualquer outro fator, como a posição topográfica, a exposição das vertentes ou a altitude (Pinheiro e Laranjeira, 2012).

\subsection{Relação entre a temperatura de superfície e os usos do solo}

A Figura 7 ilustra a distribuição dos valores de $T_{s}$ por grandes classes de uso do solo, determinadas com base na amostra definida no presente trabalho (pontos dos perfis $1 \mathrm{e}$ 2). A assinatura térmica da vegetação é notoriamente distinta - a média de $T_{s}$ é bastante inferior $\left(25,2^{\circ} \mathrm{C}\right)$ à dos restantes usos do solo, registando-se uma diferença de $5,8^{\circ} \mathrm{C}$ e $6,4^{\circ} \mathrm{C}$ em relação à $T_{s}$ média das classes de construção e de solo nu/pavimento, respetivamente. Para além disso, 75\% (3. quartil) dos valores de $T_{s}$ não ultrapassam os $26,5^{\circ} \mathrm{C}$. Pelo contrário, nas áreas construídas apenas $25 \%$ dos valores de $T_{s}$ são inferiores a $31^{\circ} \mathrm{C}$ (1. o quartil). Estes resultados demonstram bem a importância do efeito da vegetação sobre o comportamento térmico das áreas urbanas, corroborando a afirmação de Weng et al. (2004), em que: "vegetation abundance is one of the most 


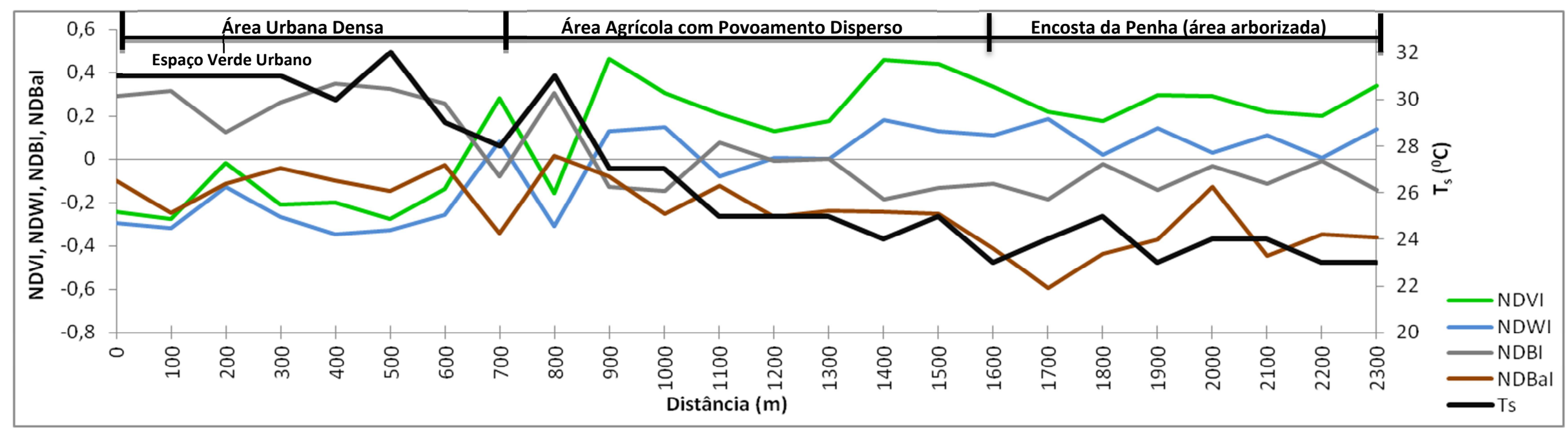

Figura 5 - Perfil centro da cidade - encosta da Penha, WNW-ESE (perfil 1): variação de Ts, NDVI, NDWI, NDBI e NDBa

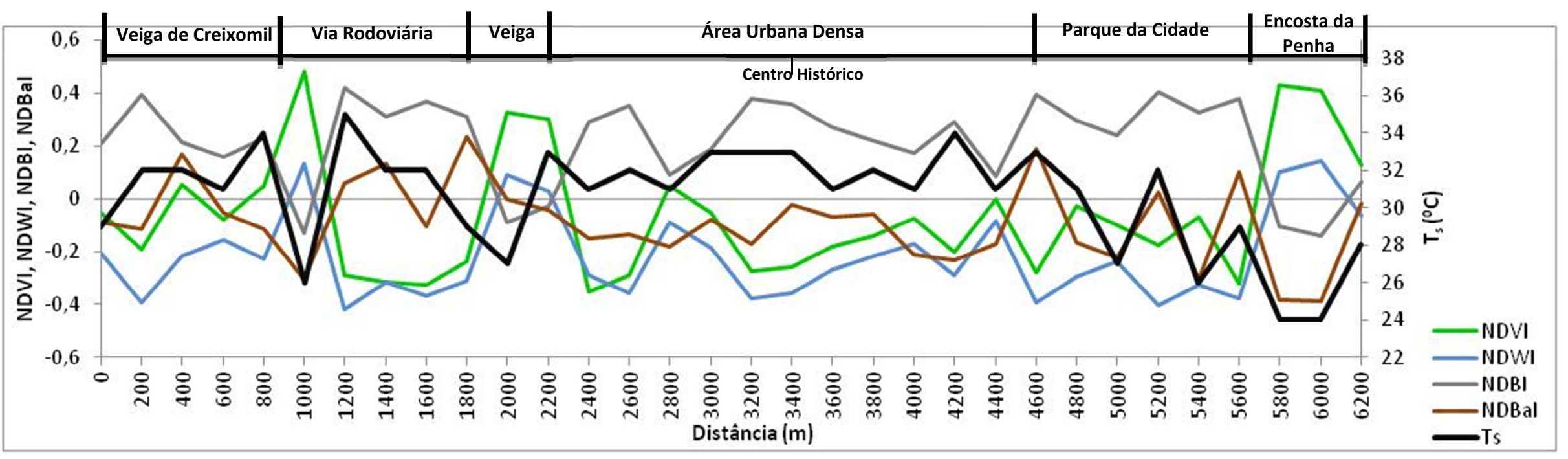

Figura 6 - Perfil veiga de Creixomil - Parque da Cidade, WSW-ENE (perfil 2): variação de Ts, NDVI, NDWI, NDBI e NDBal 
influential factors in controlling $L S T^{1}$ measures through partitioning solar radiation into fluxes of sensible and latent heat" (p.480).
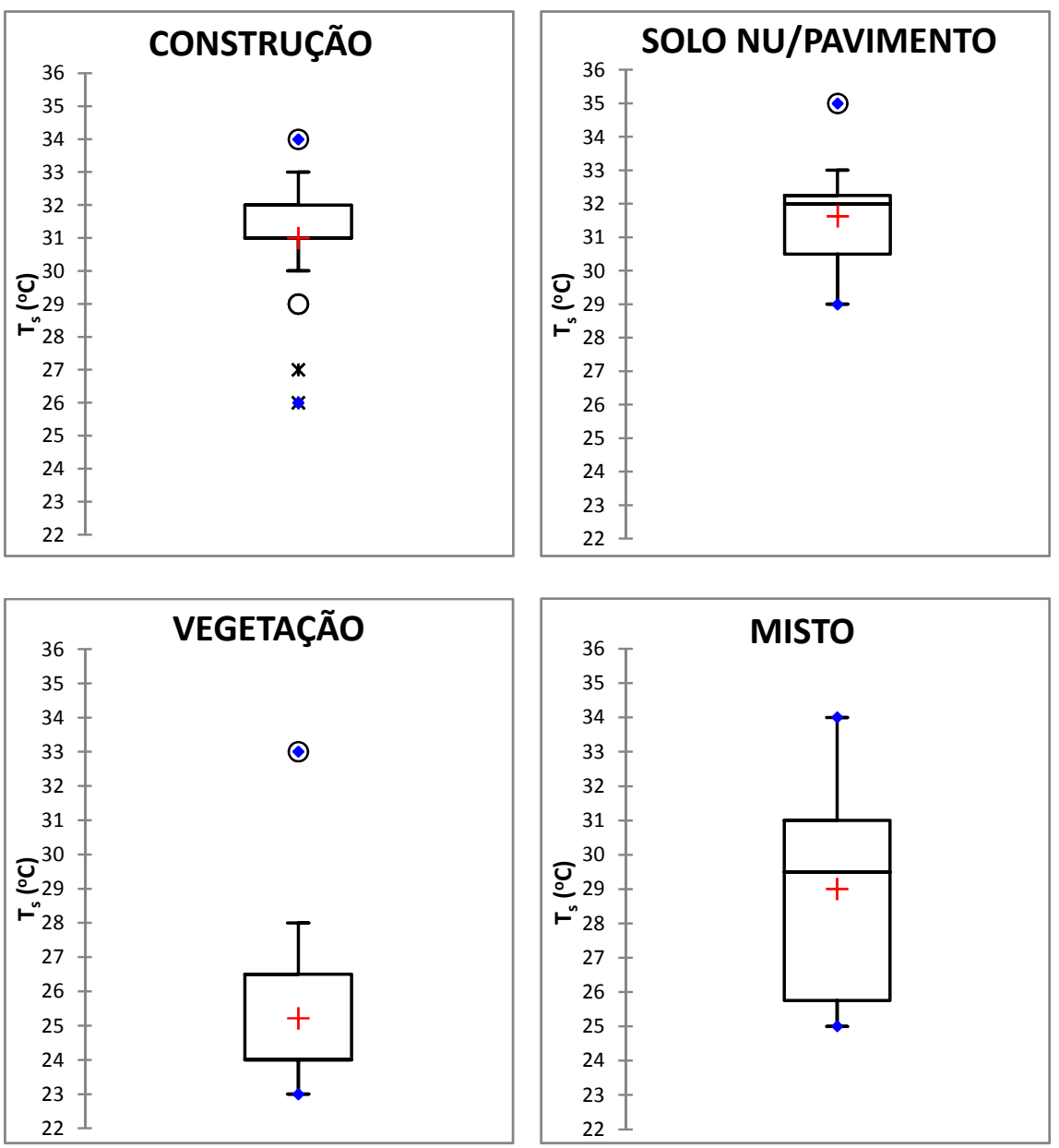

+ Média

Valores Extremos (1)

* Valores Extremos (2)

- Min/Max

Limite inferior $=x(i)$, sendo que $\{x(i)-[Q 1-1,5(Q 3-Q 1)]\}$ é mínimo e $x(i)=Q 1-1,5(Q 3-Q 1)$ Limite superior $=x(i)$, sendo que $\{x(i)-[Q 3+1,5(Q 3-Q 1)]\}$ é mínimo e $x(i)=Q 3+1,5(Q 3-Q 1)$ em que, $Q 1=1.0$ quartil; $Q 3=3$. quartil Valores que se encontram fora do intervalo ]Q1-3 (Q3-Q1; Q3+3 (Q3-Q1)[ são representados por Ж. Valores que se encontram nos intervalos [Q1-3 (Q3-Q1); Q1-1,5 (Q3-Q1)] ou [Q3+1,5 (Q3Q1); Q3+3 (Q3-Q1)] são representados por $\mathbf{O}$. Estes valores são considerados anómalos.

Figura 7 - Estatísticas descritivas de $T_{s}$ por usos do solo

O solo nu/pavimento apresenta uma assinatura térmica semelhante à da construção, embora a mediana e a média de $\mathrm{T}_{\mathrm{s}}\left(32^{\circ} \mathrm{C}\right.$ e $31,6^{\circ} \mathrm{C}$, respetivamente) sejam ligeiramente mais elevadas do que as que descrevem esta última classe $\left(31^{\circ} \mathrm{C}\right.$, em ambos os casos). Estes resultados atestam as diferenças de inércia térmica entre a maioria dos materiais

\footnotetext{
${ }^{1}$ LST (Land Surface Temperature) corresponde a outro acrónimo de temperatura de superfície frequentemente utilizado nos textos científicos em língua inglesa.
} 
de construção (em que esta é elevada) e o solo; na realidade, verifica-se que: "dry, bare, and low-density soils [...] have been linked to high $L^{2} T^{2}$ as a result of relatively low thermal inertia" (Weng et al., 2004, p.469). Desta forma, às 10h (hora local), os solos lavrados atingem $T_{s}$ mais elevadas do que as coberturas dos edifícios nas áreas construídas, pois aquecem e libertam mais rapidamente o calor sensível. Mas, por outro lado, nos espaços edificados a maior quantidade de calor armazenado, a esta hora da manhã, estará disponível para ser libertada na atmosfera urbana durante a noite, contribuindo assim para o aquecimento do ar (Lopes, 2003).

Ao agrupar uma miscelânea de vegetação rasteira e de terrenos desocupados, a classe de uso misto apresenta, tal como seria de esperar, uma maior amplitude dos valores de $\mathrm{T}_{\mathrm{s}}$ compreendidos entre o $1 . \mathrm{o}$ e $\mathrm{o} 3 .$. quartis (que correspondem a $25,8{ }^{\circ} \mathrm{C}$ e a $31^{\circ} \mathrm{C}$, respetivamente), bem como uma $\mathrm{T}_{\mathrm{s}}$ média de $29^{\circ} \mathrm{C}$, mais elevada que a da classe de vegetação (que representa essencialmente as áreas densamente arborizadas), mas inferior à dos restantes usos. Com efeito, tanto a vegetação rasteira, que se encontra frequentemente seca durante o verão, como o solo compactado (e desidratado) se caracterizam por uma reduzida evapotranspiração, o que se traduz num menor fluxo de calor latente e no aumento da $T_{s}$. Relacionando as $T_{s}$ de diversas superfícies com as temperaturas do ar numa área suburbana, durante um dia de verão (julho), Bonan (2000) verificou que pelas $10 \mathrm{~h}$, e até ao início da tarde (14h), todos os espaços verdes irrigados (relvados, canteiros de flores) apresentaram valores de $T_{s}$ inferiores aos da temperatura do ar. Pelo contrário, as $T_{s}$ de prados naturais (não irrigados), solo nu e materiais artificiais suplantaram sempre as temperaturas do ar em alguns ou várias dezenas de graus, exibindo um aquecimento diurno muito mais acentuado do que os espaços verdes.

\subsection{Padrão espacial de ventilação}

De acordo com Alcoforado et al. (2005), "o relevo constitui um primeiro fator condicionante da ventilação, ao qual deve ser acrescentada a rugosidade aerodinâmica, dependente da morfologia urbana" (p.46). Nos topos mais elevados (altitude $>340 m$ ) - 
Penha e Senhora do Monte -, praticamente sem ocupação urbana e densamente florestados (Figura 2), ocorre a formação do ar frio que escoa pelas vertentes - brisa descendente de vertente -, acumulando-se no fundo do vale, onde se situa a cidade de Guimarães e a vila de Pevidém (Figura 8). Os topos com altitude $<340 m$ e as vertentes encontram-se expostos às brisas de vertente (descendente e ascendente), canalizadas ao longo dos principais entalhes da rede hidrográfica (Figura 8). Em relação às vertentes, a existência de socalcos (Figura 9) condiciona o fluxo descendente das brisas (Figura 8). Os socalcos criam áreas aplanadas, pelo que ao comparar o declive da superfície topográfica com o calculado tendo em conta a sua presença ('declive real', de acordo com os dados da DRAPN) verifica-se, de facto, que na maior parte da área urbana de Guimarães este não ultrapassa os 5-6\%, valores comparáveis aos do fundo do vale (Pinheiro e Laranjeira, 2012). Tal situação conduz à redução da velocidade de escoamento catabático noturno do ar frio, que vai ficando retido nos socalcos, promovendo, assim, um menor arrefecimento das superfícies urbanas (Pinheiro, 2012). Por sua vez, a elevada densidade urbana nas vertentes promove o aumento da rugosidade, o que condiciona a circulação das brisas, causando a alteração da direção dos fluxos e/ou a diminuição da sua velocidade no interior da malha urbana.

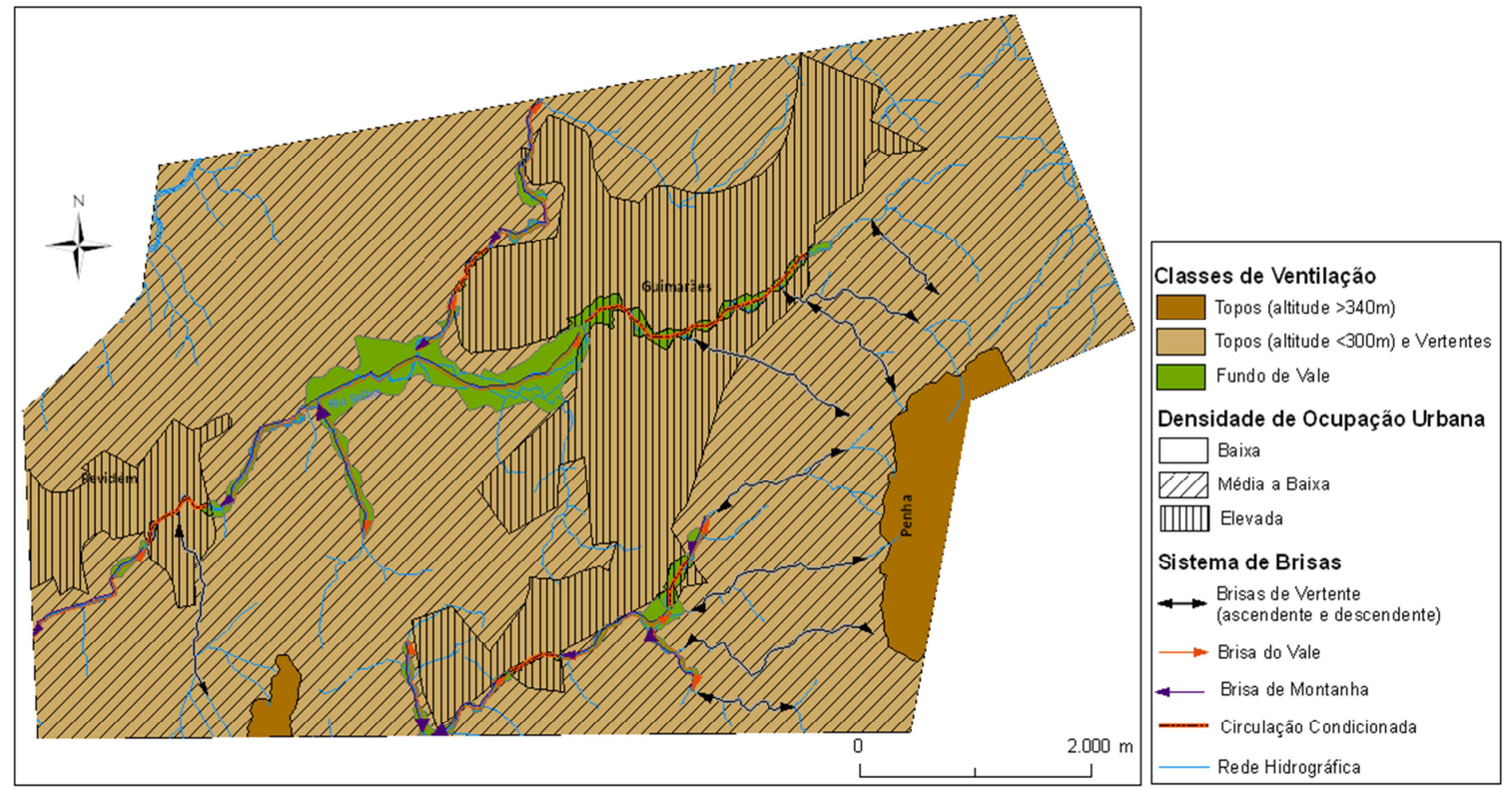

Figura 8 - Classes de ventilação e densidade urbana de Guimarães

(Fonte dos dados: CMG e DRAPN) 


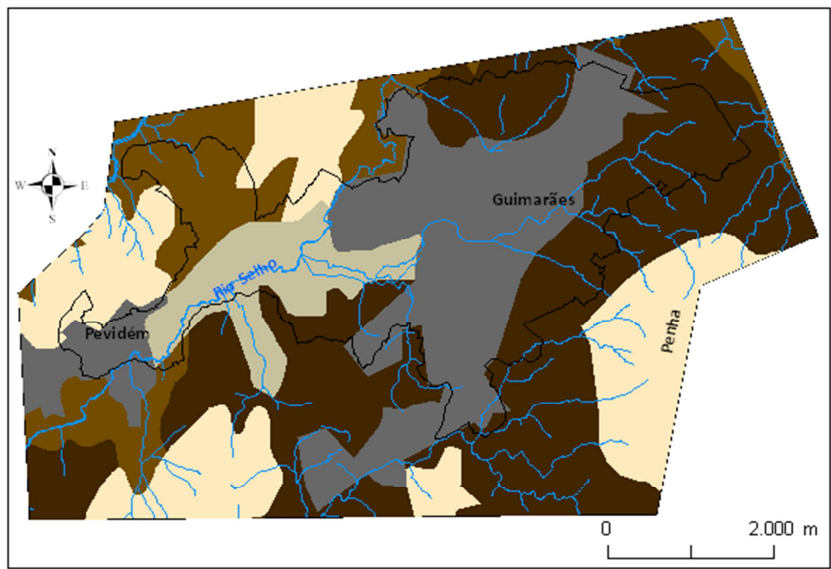

Tipo de Socalco e Percentagem (\%) de Ocupação Sem Socalcos

Socalcos Largos em 30 a $50 \%$ da Mancha

Socalcos Largos em 50 a $70 \%$ da Mancha

Socalcos Estreitos em 50 a $70 \%$ da Mancha

Urbano (sem dados)

Rede Hidrográfica

Perímetro Urbano

Figura 9 - Socalcos na área urbana de Guimarães

(Fonte dos dados: CMG e DRAPN)

As áreas do fundo do vale com ocupação urbana muito baixa sofrem um acentuado arrefecimento radiativo e acumulam o ar frio que escoa ao longo das vertentes, durante a noite; em oposição, nos dias de forte insolação, verifica-se o seu aquecimento excessivo. Nestas áreas topograficamente deprimidas, assumem particular importância "os fenómenos de drenagem noturna e de canalização do vento" (Alcoforado et al., 2005, p.50) (Figura 8). Contudo, nos núcleos de Guimarães e Pevidém a maior rugosidade urbana, aliada ao fraco declive da superfície, reduz a velocidade das brisas, podendo mesmo causar a sua interrupção (Figura 8), o que condiciona fortemente o arejamento destas áreas.

\subsection{Funções climáticas}

A análise do padrão espacial de $T_{S}$ e da ventilação na área urbana de Guimarães permitiu estabelecer as funções climáticas que cada climatopo realiza (Figura 10), designadamente: produção de ar frio; renovação do ar; e, corredores de ventilação. A importância relativa destas funções em cada climatopo foi avaliada através de uma matriz, sendo que se procurou identificar os principais condicionamentos ao seu desempenho (Tabela 2). 


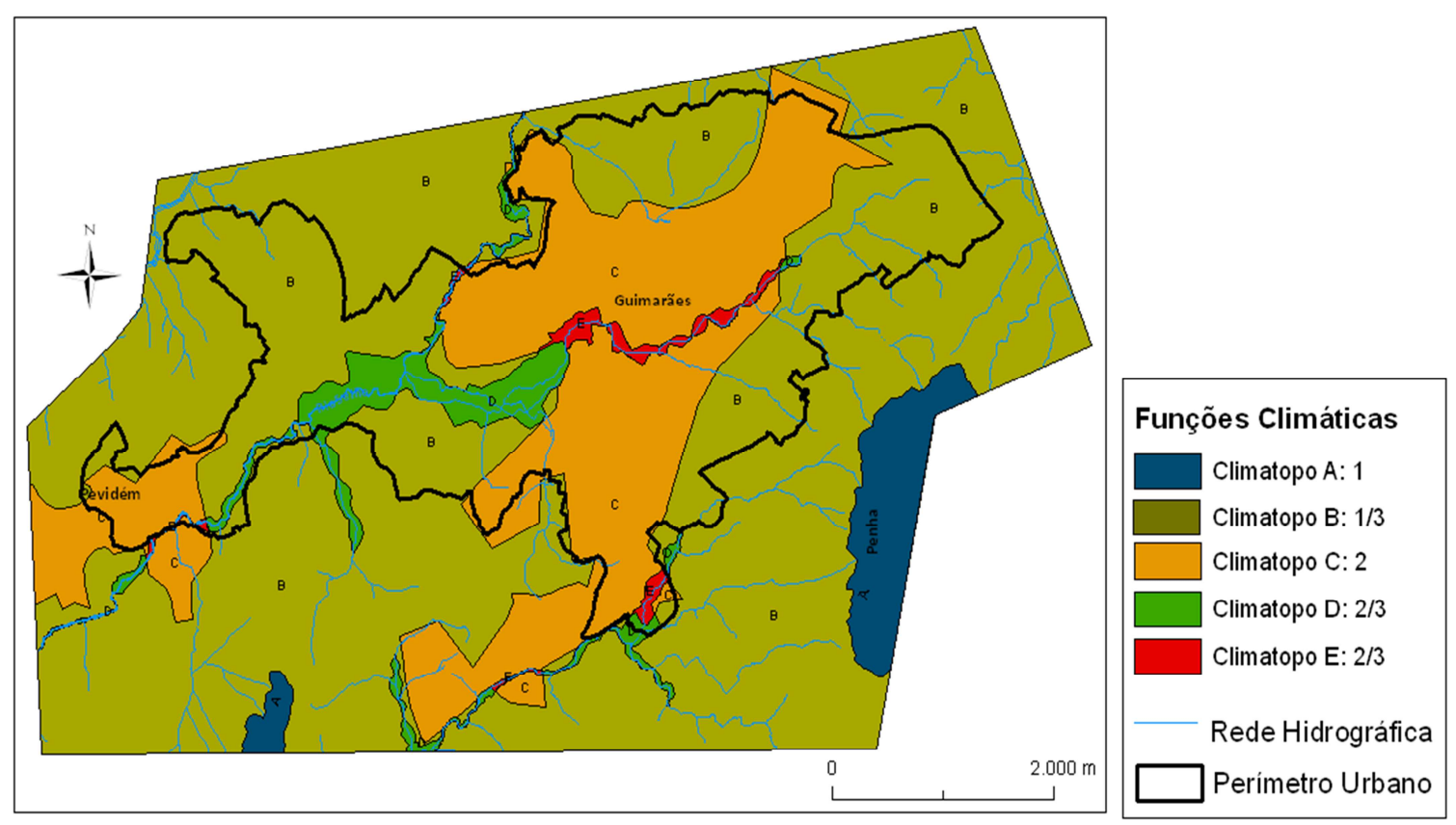

Figura 10 - Funções climáticas na área urbana de Guimarães (ver texto para explicação)

(Fonte dos dados: CMG e DRAPN)

A produção de ar frio ocorre nas áreas de topo, particularmente nas de maior altitude (mais expostas) e florestadas (climatopo A), destacando-se o monte da Penha. De facto, as áreas densamente arborizadas constituem importantes ilhas de frescura superficial, quer de dia (como comprova a distribuição espacial de $T_{s}$; Figura 3 ) quer durante a noite (Spronken-Smith e Oke, 1998; Chen et al., 2012). Porém, as ilhas de frescura superficial associadas aos espaços verdes não se devem aos mesmos fatores ao longo do dia, tal como concluíram Spronken-Smith e Oke (1998): "during the day trees may play an important role in establishing a cool park effect, perhaps through a combination of shade and evaporative cooling. At night it appears that the surface geometry and moisture status of the park are important controls on surface cooling"(p.2102). Assim, a manutenção dos espaços florestais nestas áreas é fundamental para a salvaguarda da produção local de ar frio, sendo imprescindível não edificar e impermeabilizar o solo. Sabendo que o calor armazenado, durante o dia, nas áreas construídas é devolvido à atmosfera urbana inferior ao longo da noite (Lopes, 2008), esta função climática desempenhada pelos topos revela-se de uma extrema importância no que respeita a substituição do ar quente noturno, relacionado com a formação da ilha de calor urbano 
superficial, em Guimarães, Pevidém e Urgeses. Todavia, convém acautelar dois aspetos relevantes. Por um lado, o padrão espacial de $T_{s}$ pode ser variável no espaço e no tempo, como Lopes (2008) demonstrou para Lisboa. Por outro, apesar da correlação entre $T_{s}$ e a temperatura do ar ser mais forte durante a noite, esta última é influenciada por outros fatores, entre os quais a advecção e o fator de visão do céu (sky view factor), que podem diluir tal relação (Voogt e Oke, 2003). Nesta sequência, tendo em conta que a ilha de calor noturna da atmosfera urbana inferior não foi objeto de análise, serão necessários estudos mais aprofundados sobre a relação entre $T_{s}$, a temperatura do ar e a ventilação na área urbana de Guimarães, para fundamentar e comprovar empiricamente as afirmações anteriores.

Nas áreas de topo com altitudes mais baixas (climatopo B) ainda tem lugar a produção de ar frio, mas esta função é menos significativa, como resultado da menor altitude e da ocupação urbana existente (Tabela 2). Assim, à semelhança do climatopo anterior, nestas áreas é importante manter os espaços arborizados existentes (e, quando possível, criar outros), bem como condicionar a densidade da urbanização.

Em relação ao climatopo D não existem condicionamentos à renovação do ar (Tabela 2), assumindo esta função maior importância nas margens ribeirinhas, pois o corredor de ventilação desenvolve-se primordialmente ao longo do rio Selho e da ribeira de Costa/Couros (Figura 8). A manutenção desta função depende de uma eficaz restrição da impermeabilização e da construção nos solos agrícolas aqui existentes. Por oposição, no climatopo E, a renovação do ar encontra-se muito limitada, em particular no caso do troço da ribeira de Costa/Couros que atravessa a cidade de Guimarães, e se encontra muito alterado como resultado de séculos de urbanização, fazendo atualmente parte de uma malha edificada muito densa, que dificulta a circulação das brisas junto ao solo (Pinheiro e Laranjeira, 2012). Nestas áreas é fundamental restaurar as margens ribeirinhas, através de medidas de regeneração específicas para o microclima, como a localização favorável de espaços verdes. A entrada de ar fresco na cidade de Guimarães (principal núcleo urbano da área de estudo) e na vila de Pevidém (área muito industrializada) asseguraria o necessário arejamento. 
Tabela 2 - Importância das funções climáticas na área urbana de Guimarães

\begin{tabular}{|c|c|c|c|c|c|}
\hline \multirow{2}{*}{\multicolumn{2}{|c|}{ Climatopos }} & \multirow{3}{*}{ Morfologia } & \multicolumn{3}{|c|}{ Funções Climáticas } \\
\hline & & & $\begin{array}{c}\text { Produção de ar } \\
\text { frio (1) }\end{array}$ & $\begin{array}{c}\text { Renovação do ar } \\
\text { (2) }\end{array}$ & $\begin{array}{l}\text { Corredores de } \\
\text { ventilação (3) }\end{array}$ \\
\hline A & $\begin{array}{c}\text { Topos (altitude }>340 \mathrm{~m} \text { ), com } \\
\text { baixa densidade urbana }\end{array}$ & & +++ & & \\
\hline \multirow{4}{*}{ B } & \multirow{4}{*}{$\begin{array}{c}\text { Topos (altitude }<340 \mathrm{~m} \text { ) e } \\
\text { vertentes, com densidade urbana } \\
\text { média a baixa }\end{array}$} & $\begin{array}{c}\text { Topo e setor inicial da } \\
\text { vertente }\end{array}$ & ++ & & +++ \\
\hline & & Declive $>30 \%$ & & & +++ \\
\hline & & Declive $12-30 \%$ & & & +++ \\
\hline & & Declive $<12 \%$ & & & \\
\hline C & $\begin{array}{l}\text { Topos (altitude }<340 \mathrm{~m} \text { ) e } \\
\text { vertentes, com elevada } \\
\text { densidade urbana }\end{array}$ & & & & \\
\hline D & $\begin{array}{l}\text { Fundo de vale, com baixa } \\
\text { densidade urbana }\end{array}$ & & & +++ & +++ \\
\hline $\mathrm{E}$ & $\begin{array}{c}\text { Fundo de vale, com elevada } \\
\text { densidade urbana }\end{array}$ & & & & \\
\hline
\end{tabular}

+++ - muito importante; ++ - importante; .... - função condicionada pela ocupação urbana; .... função condicionada pela existência de socalcos; .... - função condicionada pela existência de socalcos, pela ocupação urbana e dependente da localização favorável dos espaços verdes; .... função dependente da localização favorável de espaços verdes.

Os corredores de ventilação estão presentes em todos os climatopos, com a exceção dos topos (Tabela 2). Nas vertentes incluídas no climatopo B, esta função é condicionada tanto pela existência de socalcos como pela ocupação urbana pois, apesar desta se caracterizar por uma densidade média a baixa, ocorre ao longo das linhas de água (Pinheiro, 2012), que formam os entalhes por onde preferencialmente circularão as brisas de vertente. Para salvaguardar esta função é fundamental impedir a construção junto a estes entalhes e, através de espaços verdes, melhorar e/ou restaurar a conexão entre os corredores de ventilação, particularmente nos locais onde a urbanização é mais densa. Nos climatopos C e E (áreas urbanas consolidadas), o desempenho desta função encontra-se muito limitado pela urbanização e as alterações que esta provoca na rede hidrográfica. Assim, nestas áreas, à semelhança do sugerido para o climatopo $B$, é 
necessário recriar a conexão entre os corredores de ventilação, de modo a minimizar os impactes da urbanização sobre a circulação à superfície destes ventos locais.

\section{Conclusão}

Em Portugal, salvo a preocupação com a qualidade do ar, não existe nenhuma legislação que salvaguarde e promova diretamente a dinâmica climática local, apesar do reconhecimento geral de que a sua desregulação pode acarretar graves problemas ambientais, em particular nas áreas mais densamente urbanizadas, associados ao seu sobreaquecimento e à alteração das condições de ventilação à superfície. Os resultados do presente estudo demonstram bem a relação espacial existente entre as $T_{s}$ mais elevadas (indicadoras de fontes de calor) e os centros urbanos de Guimarães, Pevidém e Urgezes, onde predominam as superfícies artificiais. Por sua vez, a importância dos espaços verdes, para o conforto térmico urbano, é salientada pela distribuição espacial das $T_{s}$ mais baixas, associadas às áreas florestadas, destacando-se claramente o monte da Penha. Neste contexto, a Estrutura Ecológica Municipal (EEM) - figura de delimitação obrigatória, de acordo com o Decreto-Lei 380/99, de 22 de Setembro (que estabelece o regime jurídico dos instrumentos de gestão territorial) - pode assumir um papel muito importante na salvaguarda de topoclimas e microclimas favoráveis, já que a estrutura ecológica deve integrar as noções de continuum naturale e de aptidão ecológica da paisagem. No caso da área urbana de Guimarães, encontram-se afetas à EEM ${ }^{3}$ as áreas fundamentais à produção de ar frio, à renovação do ar e aos corredores de ventilação i.e., os espaços florestais das áreas de topo, as margens ribeirinhas agrícolas, os entalhes de vertente (linhas de água) e os espaços verdes urbanos -, podendo-se, assim, manter e valorizar estas funções climáticas, pelo que esta figura se revela de extrema importância para a sustentabilidade ambiental urbana, no atual quadro legal. Todavia, a salvaguarda das linhas de água, nas vertentes, e das áreas ribeirinhas do fundo do vale não decorre diretamente da sua relevância para a dinâmica climática, estando antes relacionada com a proteção dos recursos hídricos e o risco de inundação (Pinheiro,

\footnotetext{
${ }^{3}$ Versão disponível para discussão pública do PDM de Guimarães.
} 
2012). De facto, é importante realçar que em todo o regime de gestão da EEM de Guimarães apenas uma ação (classificada de 'privilegiada') se refere diretamente ao clima, e à necessidade de redução das amplitudes térmicas diurnas (cf. alínea c, n. 01 do artigo 11.9 ), revelando a ainda incipiente consideração dada ao clima no âmbito do ordenamento do território vimaranense.

\section{Referências}

Acero, J. A.; Arrizabalaga, J.; Kupski, S., Katzschner, L. (2013). “Deriving an Urban Climate Map in coastal areas with complex terrain in the Basque Country (Spain)". Urban Climate, 4:35-60

Alcoforado, M.J.; Lopes, A.; Andrade, H.; Vasconcelos, J. (2005). Orientações Climáticas para o Ordenamento em Lisboa. Lisboa, Centro de Estudos Geográficos da Universidade de Lisboa, 83 p.

Alcoforado, M.J.; Andrade, H.; Lopes, A.; Vasconcelos, J. (2009). “Application of climatic guidelines to urban planning: the example of Lisbon (Portugal)". Landscape and Urban Planning 90(1-2):56-65.

Andrade, H. (2003). Bioclima Humano e Temperatura do Ar em Lisboa. Doutoramento, Universidade de Lisboa.

Andrade, H. (2005). "O clima urbano: natureza, escalas de análise e aplicabilidade". Finisterra XL(80):6791.

Andrade, H.; Vieira, R. (2007). "A climatic study of an urban green space: the Gulbenkian Park in Lisbon (Portugal)”. Finisterra XLII(84): p.27-46.

Armas, R.; Caetano, M. (2005). Revisão Bibliográfica sobre a Utilização de Imagens de Satélite para Detecção de Áreas Ardidas e de Cortes e Novas Plantações Florestais (Relatório técnico). Lisboa, Instituto Geográfico Português, 65p.

Bonan, G.B. (2000). "The microclimates of a suburban Colorado (USA) landscape and implications for planning and design". Landscape and Urban Planning 49(3-4): 97-114.

Câmara Municipal de Guimarães (2012). Regulamento do PDM de Guimarães. (http://www.cmguimaraes.pt/PageGen.aspx?WMCM_Paginald=40456).

Cao, X.; Onishi, A.; Chen, J.; Imura, H. (2010). "Quantifying the cool island intensity of urban parks using ASTER and IKONOS data". Landscape and Urban Planning 96(4): 224-231.

Chen, X.; Zhao, H.; Li, P.; Yin, Z. (2006). "Remote sensing image-based analysis of the relationship between urban heat island and land use/cover changes". Remote Sensing of Environment 104(2):133-146.

Chen, Z.; Gong, C., Wu, J.; Yu, S. (2012). "The influence of socioeconomic and topographic factors on nocturnal urban heat islands: a case study in Shenzhen, China". International Journal of Remote Sensing 33(12):3834-3849.

Costa, D.; Silva, H.; Peres, L. (2010). "Identificação de ilhas de calor na área urbana de Ilha Solteira (Sp) através da utilização de geotecnologias”. Engenharia Agrícola 30(5): 974-985.

Costa, T.; Laranjeira, M.M. (2012). Condições térmicas avaliadas por índices urbanísticos e temperaturas de superfície numa cidade de pequena dimensão (Fafe, Portugal). Cidades, Criatividade(s) e Sustentabilidade(s): Actas das VIII Jornadas de Geografia e Planeamento. A. Vieira; F. Costa; P. Remoaldo (Eds.). Guimarães, Departamento de Geografia/Universidade do Minho: 314-321.

Deng, C.; Wu, C. (2013). "Examining the impacts of urban biophysical compositions on surface urban heat island: a spectral unmixing and thermal mixing approach". Remote Sensing of Environment 131: 262-274.

Eum, J.; Scherer, D.; Fehrenbach, U.; Woo, J. (2011). "Development of an urban landcover classification scheme suitable for representing climatic conditions in a densely built-up Asian megacity". Landscape and Urban Planning 103: 362-371. 
Gao, B. (1996). “NDWI: a normalized difference water index for remote sensing of vegetation liquid water from space". Remote Sensing of Environment 58(3): 257-266.

Landsat Project Science Office (2001). Landsat 7 Science Data Users Handbook. NASA, 186 p. (http://landsathandbook.gsfc.nasa.gov/pdfs/Landsat7Handbook.pdf).

LeaL, C.; Ganho, N.; Cordeiro, A. R. (2008). "O contributo dos espaços verdes da cidade de Coimbra (Portugal) no topoclima, microclima e no conforto bioclimático". Cadernos de Geografia 26/27: 331-341.

Lopes, A. (2003). Modificações no Clima de Lisboa como Consequência do Crescimento Urbano: Vento, Ilha de Calor de Superfície e Balanço Energético. Doutoramento, Universidade de Lisboa.

Lopes, A. (2008). “O sobreaquecimento das cidades: causas e medidas para a mitigação da ilha de calor de Lisboa". Territorium 15: 39-52.

Pinheiro, C.A. (2012). Contributo da Estrutura Ecológica para a Sustentabilidade Urbana: O Caso de Guimarães. Mestrado, Universidade do Minho.

Pinheiro, C.A.; Laranjeira, M.M. (2012). Integração das funções climáticas no contexto da estrutura ecológica como contributo para a sustentabilidade ambiental urbana: o caso de Guimarães. Cidades, Criatividade(s) e Sustentabilidade(s): Actas das VIII Jornadas de Geografia e Planeamento. A. Vieira; F. Costa; P. Remoaldo (Eds.). Guimarães, Departamento de Geografia/Universidade do Minho: 281-288.

Purevdorj, T.S.; Tateishi, R.; Honda, Y. (1998). "Relationships between percent vegetation cover and vegetation indices". International Journal of Remote Sensing 19(18):3519-3535.

Scherer, D.; Fehrenbach, U.; Beha, H.; Parlow, E. (1999). "Improved concepts and methods in analysis and evaluation of the urban climate for optimizing urban planning processes". Atmospheric Environment 33(24-25): 4185-4193.

Spronken-Smith, R.; Oke, T. (1998). "The thermal regime of urban parks in two cities with different summer climates". International Journal of Remote Sensing 19(11):2085-2104.

Townend, J. (2002). Practical Statistics for Environmental and Biological Scientists. Chichester, John Wiley \& Sons.

Voogt, J.; Oke, T. (2003). "Thermal remote sensing of urban climates". Remote Sensing of Environment 86:370-384.

Weng, Q. (2009). "Thermal infrared remote sensing for urban climate and environmental studies: methods, applications, and trends". ISPRS Journal of Photogrammetry and Remote Sensing 64: 335-344.

Weng, Q.; Lu, D.; Schubring, J. (2004). "Estimation of land surface temperature-vegetation abundance relationship for urban heat island studies". Remote Sensing of Environment 89(4):467-483.

Wilson, J.; Clay, M.; Martin, E.; Stuckey, D.; Vedder-Risch, K. (2003). “Evaluating environmental influences of zoning in urban ecosystems with remote sensing". Remote Sensing of Environment 86(3): 303-321.

Xiong, Y.; Huang, S.; Chen, F.; Ye, H.; Wang, C.; Zhu, C. (2012). "The impacts of rapid urbanization on the thermal environment: a remote sensing study of Guangzhou, South China". Remote Sensing 4(7): 20332056.

Zha, Y. ; Gao, J.; Ni, S. (2003). "Use of normalized difference built-up index in automatically mapping urban areas from TM imagery". International Journal of Remote Sensing 24(3):583-594.

Zhao, C.; Fu; G.; Liu, X.; Fu, F. (2011), “Urban planning indicators, morphology and climate indicators: a case study for a north-south transect of Beijing, China". Buildings and Environment 46: 1174-1183.

Zhao, H.; Chen, X. (2005). "Use of normalized difference bareness index in quickly mapping bare areas from TM/ETM+". Geoscience and Remote Sensing Symposium 3(25-29): 1666-1668.

Zhou, W.; Huang, G.; Cadenasso, M. (2011). “Does spatial configuration matter? Understanding the effects of land cover pattern on land surface temperature in urban landscapes". Landscape and Urban Planning 102: 54-63. 